Journal Home Page:

http://perlinguam.journals.ac.za

\section{Per Linguam}

A Journal for Language Learning Tydskrif vir Taalaanleer

\title{
TRAINING PRIMARY SCHOOL TEACHERS FOR LITERATURE TEACHING: A VIEW FROM BOTSWANA.
}

\author{
Deborah V Sanoto, Botswana Open University
}

Christa van der Walt, Stellenbosch University

Primary school level is where the love for reading and understanding of literature starts, and for teachers to succeed in the teaching of reading and literature, they need to display certain habits and practices in their English as a second language (ESL) classrooms. One of the habits is reading extensively and developing a passion for reading. In this study, the impact of the in-service training of a specific group of primary school teachers in Botswana was explored by means of questionnaires and interviews. This was done to investigate the strategies employed by these teachers in terms of their content knowledge and pedagogical content knowledge (PCK) as they teach literature to Standards 1 to 7 ESL pupils. The results from the questionnaires and the interviews allowed us to determine the start of problems with literature teaching. The questionnaire data gave an overview of the reading culture that prevailed in this case, and the interviews made it possible to enhance the picture provided in the questionnaires. This study revealed that the in-service teacher trainees lacked the requisite habits and practices required of a teacher of literature. We therefore argue that these teachers would fail to translate literary concepts into PCK because they had not gained any experience in analysing and evaluating full literary texts during their own schooling or teacher training.

Keywords: Literature teaching, pedagogical content knowledge, English as a second language, Botswana primary schools, in-serving teacher trainees

\section{INTRODUCTION}

Reading extensively and developing a passion for reading have been shown to be indispensable conditions for the successful teaching of literature. This study explored the impact of the strategies employed by in-service teacher trainees in terms of their content knowledge and pedagogical content knowledge (PCK) as they teach literature to primary school Standard 1 to 7 (Grade 1 to 7 in South Africa) pupils. Primary school level is where the love for reading and understanding of literature starts. Therefore, the school curriculum requires that teachers focus explicitly on the development of reading and comprehension skills, coupled with the development of basic literary concepts.

\section{Background of the research problem}

The research project was undertaken against the background of the first author's experiences as a lecturer for the Diploma in Primary Education by Distance Education (DPE-DE) English Studies in Botswana. She has, through interaction with students at secondary and tertiary level for more than 20 years, observed a number of problems that, in her view, explain the perceived lack of 
interest in their English Studies at diploma level and the resultant lack of a reading culture. The following concerns acted as a stimulus to venture into this current study:

- Teacher trainees generally seem to have a low level of proficiency in English and they seem to depend on traditional methods of teacher-fronted classroom teaching.

- The majority have a Junior Secondary Certificate, which means that they have not accessed foundational studies in literature as a separate subject, as is the case at senior secondary level. This situation is not helped by the study of prescribed literature texts that have been in the syllabus for more than 10 years and are likely to have become boring and monotonous for the lecturer, and presumably for the teacher trainees as well.

- There does not seem to be a reading culture in Botswana primary schools, which is evident in the lack of enthusiasm to acquire copies of the prescribed literature texts in the case of some teacher trainees (both in the conventional and the distance education setup).

- The study centres for distance education students are under-resourced in terms of material and infrastructure and, at times, they overstretch their human resources.

- Teacher training college students need to manage their in-service studies and family commitments, a situation which usually results in frustration and failure to complete their studies.

The context for this research was that of in-service teacher trainees who had acquired their Diploma in Primary Education by Distance Education. These teachers were at Botswana primary schools and were involved in the teaching of English language and literature to pupils who learn English as a second language (ESL). The teachers involved in this study taught different grades ranging from Standard 1 to 7 (Grade 1 to 7 in the South African system).

This study investigated in-service teacher trainees for the Diploma in Primary Education by Distance Education, specifically in English Studies. The study sought to understand the reading behaviour and habits of these students who were studying literature in English to explore their perceptions of the subject and the impact of their studies on their pupils. It is important to note that primary education lays the basic foundation for all other levels of educational development. This places considerable responsibility on the primary school teacher to develop versatile and holistic learners. It is necessary to take into account that the primary school level is the stage at which a love of reading in any language starts for children, and if it is not acquired effectively, it can adversely affect the pupils' passion for reading and, by extension, appreciation of studying literature in the future. Even though children generally start reading in their mother tongue, Setswana in this study, literacy skills and a positive attitude to reading are intended to transfer to English (the language of learning and teaching from the fourth grade onwards). There is a great responsibility on teachers to foster this appreciation. However, the teachers may exhibit characteristics that have been identified in research as 'aliterate', according to Rasey (2009: 2). These are 'capable readers who choose not to read'.

Were there 'aliterate' teachers among our selected research population? These teachers would typically advise the parents of their pupils to read daily to their children, while they as teachers would fail to take their own advice. This could be reflected in in-service teacher trainees' classroom decisions with regard to reading and writing lessons. Teachers with a negative attitude towards reading will probably perpetuate the same feeling in their classrooms. Applegate and 
Applegate (2004: 555) refer to this as the 'Peter Effect', referring to Peter in the Bible who could not give what he himself did not have. Conversely, teachers with positive reading experiences are likely to share that joy of reading with their students. These are the issues that we wanted to explore with the participants in this project.

\section{Theoretical background}

The theoretical framework relevant to this study is that of Shulman (1986), in the form of PCK. Shulman's (1986) concept is focused on the strength of subject matter that teachers acquire in their training, and how they translate that subject knowledge into the knowledge required for teaching the subject. In other words, content knowledge is not sufficient for a teacher and may not effectively transform into instructional material. Teachers may have content knowledge but fail to teach the content successfully.

In the case of this study, there was a strong suspicion that teachers did not have sufficient content knowledge to transform into PCK. The study therefore tried to ascertain the availability of resources to support the acquired knowledge base as well as how the teachers utilised these resources. In the process, the in-service trainees' strategies and classroom practices were brought to the fore. According to Shulman (1987: 9):

The teacher of English should know English and American prose and poetry. Written and spoken language use should be familiar with the critical literature that applies to particular novels or epics that are under discussion in class. Moreover the teacher should understand alternative theories of interpretation and criticism, and how these might relate to issues of curriculum and of teaching.

We (as authors) understand this to mean, for example, that a teacher who is teaching a play written by Shakespeare should have knowledge of the Elizabethan age to understand the background that influenced the themes under discussion. In the African context, we would include literature written in Africa for its pupils and teachers. Teaching as a learned profession therefore dictates that teachers should be part of a scholarly community where ideas and insights are shared.

The teacher must keep abreast of research innovations that take place in the field of teaching. He or she must not only understand the structures of the subject matter, but, as Shulman emphasises (1987: 9), 'the teacher must also have a broad liberal education that serves as a framework for old learning and as a facilitator for new understanding'. Teachers, for instance, need to be able to situate the text in their particular context and approach it from, for example, a feminist or an African literature perspective, and know how to link this to the prescriptions of the curriculum.

Although we may not necessarily agree with the necessity of a liberal education, which is related to imparting general knowledge that develops intellectual abilities rather than the development of specific skills, we can agree with Shulman's view (1987: 7) that 'teaching necessarily begins with a teacher's understanding of what is to be learned and how it is to be taught'. He continues to emphasise that teaching proceeds through a number of activities in which the students are accorded instructions and opportunities for learning. Ultimately, teaching concludes with new understanding by both the teacher and the students.

Per Linguam 2018 34(2):30-51

http://dx.doi.org/10.5785/34-2-785 
The teachers in this current study had different backgrounds with regard to literature studies. Some held the entry qualifications of the Botswana General Certificate in Secondary Education (BGCSE), which includes Literature Studies as an optional subject, while others held the Junior Certificate in Education (JCE), which excludes it. Shulman (1986: 5) underscores the importance of thorough teacher education by pointing out that 'the person who presumes to teach subject matter to children must demonstrate knowledge of that subject matter as a prerequisite to teaching'. The implication of the disparity in teaching qualifications of the teacher trainees is that teachers with the JCE do not have the requisite content knowledge of literature on which to build PCK to teach their subject, and literature in particular, properly. That is why they need to study literature, as well as the methodology for teaching literature, during the in-service programme.

\section{The status of literature as a subject in Botswana's education system}

English has assumed a double role as the medium of instruction and the official language in Botswana schools from primary level to tertiary education. At primary and junior secondary levels (ages 7 to 16), English language and literature are not taught as separate subjects, as the two aspects complement each other. The approach is to offer literature in language teaching. The teaching of literature focuses mainly on the enjoyment of texts read and the overall language development of the child, with less emphasis on details of literary criticism. Generally, the aim is to promote a reading culture in the pupils by giving them an opportunity to develop their interest in reading. At senior secondary level (ages 17 to 19), Literature in English is offered as an optional subject, and students at this level usually are encouraged to have passed their English language examination at junior certificate (JC) level with grades between $\mathrm{A}$ and $\mathrm{C}$ to gain access to the subject as an elective.

In the senior secondary school syllabus for literature in English, justification for the inclusion of literature in the curriculum is to build on the 10-year basic education programme with particular attention to the development of an all-round individual (Department of Curriculum Development and Evaluation, 1998:i). Furthermore, literature in the curriculum is meant to allow students to develop a positive self-image (who am I?), and an understanding of concepts of the communities to which they belong (cultural and national identity). Literature further enhances reading widely, by cultivating a reading culture.

We need to note here that literature offered at junior secondary level provides a foundational base for students at senior secondary level, and this was proved true when Literature in English as a subject was excluded from the curriculum in 1988, with the introduction of the two-year junior secondary programme, which replaced the three-year JC programme. Instead, Literature in English was offered as an optional subject at senior secondary level. The reasons for excluding literature, as we gather from the report on a national conference on literature in language teaching, seemed to be politically motivated with economic implications (University of Botswana, English Department, 1993: 1). For instance, the government had to scale down free basic education from 10 years to nine years. Generally, the decision was informed by a lack of understanding of (i) the role of literary works in appealing to all sections of society, and (ii) literature as a powerful weapon in favour of or against existing social structures. For pupils, in addition to improving on their acquisition of the English language, studying literature is expected to develop fluency in language use and to build vocabulary. According to Malaba (2006: 13), 
Literature enables us to explore our lives and circumstances; it pinpoints the challenges of our times and can help us to engage, either philosophically or in more concrete ways, in endeavors to ameliorate our societies. It also has great therapeutic value, in terms of recreation and can enhance our appreciation of languages.

In the view of the authors of this article, by harnessing literature, Botswana's wealth of different languages and cultural traditions would be recognised, supported and strengthened within the education system. The curriculum developers of the time seem to have lacked understanding of the significance of literature studies in the education system.

The two-year junior secondary level was in existence from 1988 to 1996, and during that period the teaching of literature in the curriculum effectively ended. This was evident from the dwindling numbers of students in senior secondary schools that opted for the subject. Some schools in the same period could not register any students for Literature in English final examinations in a particular year. The subject was rated as a 'failing' one (in other words, the failure rate was relatively high), and some teachers discouraged their students from choosing the subject.

These experiences with regard to Literature as a subject brought into question the quality of teaching of the subject, especially to DPE-DE students, some of whom were without the necessary foundation to teach English at the junior secondary level. The reason for this is that they were trained to teach English at the foundational level of education, i.e., primary school level, where literature (supposedly) does not feature. At primary school level, particularly lower primary level, the teachers' focus leans more towards teaching reading and cultivating a love of reading in the pupils; a focus that is not generally assumed to be literary. At junior secondary level (some of the in-service teacher trainees had gone that far in their secondary education), the teaching of literature is not offered separately from English as a subject, as is the case at senior secondary education level. The DPE-DE trainees are therefore faced with the mammoth task of laying a proper foundation for literary studies. The burden on the primary school teachers presumably becomes worse in an era where there is a gap in the curriculum that does not offer literature at all at junior secondary level.

\section{The role of literature in the in-service teacher education curriculum}

As pointed out above, one of the problems with the teaching of literature at school level is the preparedness of teachers. In studying the role of literature in in-service language teacher education programmes, the project under discussion here included investigating the reading patterns of the teacher trainees, in order to gauge their reading passion as revealed by the reading of prescribed literary texts. These texts are prescribed because they involve the development of analytical skills and encourage interaction with the characters in the texts. The texts are complex and are meant to equip learners with the ability to unravel the multiple layers of meaning found in the text. The Curriculum for Diploma in Primary Education (2009: 76) stipulates that the English course aims at:

producing teachers whose spoken and written English is of high standard and will be good models for their learners... and sufficiently grounded in the English language and Literature teaching methods and...strategies as a second language to learners of diverse Per Linguam 2018 34(2):30-51 
abilities, social, cultural and linguistic backgrounds.

The importance of literature in a society cannot be underestimated. According to Cairney (2011: 9), and we agree with him,

literature is not just about story; it is about life and one's world. It can act as a mirror to enable readers to reflect on life's problems and circumstances; a source of knowledge; a means to peer into the past, and the future; a vehicle to other places; a means to reflect on inner struggles; an introduction to the realities of life and death; and a vehicle for the raising and discussion of social issues.

We therefore argue that it is important that teachers of literature should display not only a love of teaching the subject, but also a passion for reading extensively to the extent that they, in their teaching of literature, successfully 'open up worlds not normally available to be experienced first-hand by children' (Cairney 2011: 9). It is undoubtedly the case that, if the teachers become avid readers, there is a strong possibility that their pupils will copy their behaviour and ultimately possess a love for reading and for studying literature.

The debate about the place of literature in language curricula is a concern not only in Botswana, but worldwide. Different scholars have advocated for the inclusion of literature in the L2 curriculum: Smit (2009: 84) argues that literature assists 'to promote greater tolerance for cultural differences' for both the learners and the teachers. Hernandi (2002: 30) argues that, besides promoting cultural tolerance in both the ESL learner and the ESL teacher, 'literature...promotes students' creativity', and McKay (1982: 531) makes this explicit by claiming that the study of literature includes a 'transfer of imaginative energy from the Literature to the student'. Furthermore, the student's interaction with the literary texts will improve reading proficiency, which further contributes to his or her academic and occupational objectives. Smit (2009: 83) emphasises that literature:

is full of real life language in different situations, which can provide a variety of models of communication. The study of literature thus teaches the ability to interpret discourse which can be applied inside, as well as outside the learning situation, and in a range of language uses both literary and non-literary.

In the African context, Malaba (2006: 3) advocates for the centrality of literature in the curriculum of universities in Africa. He argues that literary studies play a pivotal role in 'defining human values' and therefore deserve funding and support similar to that given to science and technology. Malaba (2006: 13) is further of the opinion that:

literature enables us to explore our lives and circumstances; it pinpoints the challenges of our times and can help us to engage, either philosophically or in more concrete ways, in endeavors to ameliorate our societies... and can enhance our appreciation of languages.

For the purposes of this study, then, literature is understood to refer to creative and fictional texts that are complex, and require analysis and interpretations that are aligned to our lives and perspectives. In terms of the study and the curriculum requirements that we discuss later, texts at primary schools would include literature for small children, including poems, rhymes, songs, 
stories and role playing. It is crucial, though, that the texts cater for the different reading levels of the pupils, who at primary school level are developing reading fluency. Our understanding of literature is derived from the authors that we discussed in the previous paragraphs. Readers of literature need to treat it as a mirror through which they can reflect on life problems and circumstances. On the other hand, teachers should teach literature effectively so that it not only affords their pupils the experience of 'new worlds', but also enhances their tolerance of cultural differences.

\section{The curriculum for primary school English in Botswana}

In Botswana, English is an official language, and the primary English syllabus (Department of Curriculum Development and Evaluation, 2011: 1) stipulates that the teaching of English at primary level is pivotal to it being a 'major learning tool; in and outside the classroom, through which a very substantial portion of the national curriculum, continuing education and vocational programmes are presented to and accessed by learners'. The syllabus (Department of Curriculum Development and Evaluation, 2011: 1) further underpins the learners' need to enhance their communicative and literacy skills in English as they develop knowledge of the language as a school subject.

\section{Lower primary English}

The primary school curriculum is divided into two syllabi. The first directs the first four years of primary English in Botswana (Standards 1 to 4). It also outlines the various language competencies and skills required in the early stages of learning English. The second syllabus targets Standards 5 to 7, and emphasises the three years of upper primary English language teaching in Botswana.

The lower primary syllabus attainment targets put emphasis on the process of equipping pupils with reading skills by highlighting the following (Department of Curriculum Development and Evaluation, 2011: v):

- Read aloud or silently from a text and show understanding.

- Read with fluency, accuracy and understanding both for information and pleasure.

- Read accurately and with understanding straightforward signs, notices and labels.

- Predict what might happen next in a story.

The references to reading for pleasure and predicting what might happen in a story imply that teachers will need to include children's literature in their lessons. In the next phase, starting with Standard 4, pupils are explicitly exposed to the skill of 'distinguishing between different genres, e.g. prose/story; drama/play/dialogue' and expected to also 'demonstrate awareness of character and dialogues in stories' (Department of Curriculum Development and Evaluation, 2011: 3). One could reasonably expect that pupils will have developed the beginnings of a personal culture of reading at that stage. In the first three years, the focus is on 'how to open or position a book while turning pages'; 'read for general information and knowledge'; and 'understand the linear and page sequence of a book' (Department of Curriculum Development and Evaluation, 2011: 3).

When one looks at the attainment targets in terms of reading at upper primary school level, it Per Linguam 2018 34(2):30-51 
becomes clear that the lower primary level provides the foundation for the levels that follow (Department of Curriculum Development and Evaluation, 2011: 3):

By the end of standard seven, learners should have further developed the language skills of listening, speaking, reading and writing in English to be able to:

- Read independently for information and pleasure different types of literature including poetry, drama and prose within a basic vocabulary level of 2000 words

- Use different graphic sources of information to draw logical conclusions

- Read and understand a range of basic printed matter used in everyday communications and transactions

- Use different reference materials such as the dictionary and the telephone book appropriately for different purposes

- Infer the meaning of more difficult words and unfamiliar words and phrases in context

- Speculate what could happen in a story if circumstances change

- Distinguish between fact and opinion in a variety of texts

- Combine the sense of all separate pieces of information or episodes in a text, so as to understand the whole message

- Analyse and evaluate information in a variety of written texts in order to form opinions and judgments

- Read critically to understand both the gist and specific details of texts read.

The primary English syllabus does not include a list of literary texts to be studied by the learners. The teachers are expected to infuse literature teaching through the reading materials of their choice, including poetry, drama and prose. Therefore, literature lessons at primary school level are regarded as reading lessons. How this might be problematic is elaborated on in the next section and particularly in the research findings below.

\section{RESEARCH DESIGN FOR THE STUDY}

This study adopted a case study research design because it focused on a specific cohort of students and a specific subject of study. Punch (2009: 119) strongly advocates for a case study because 'it has a holistic focus, aiming to preserve and understand the wholeness and unity of the case', while Creswell (2003: 15) explains that case studies allow the researcher to conduct an in-depth study of a programme, event, a process or one or more individuals. In this study, the focus was on the 2008 cohort for the DPE-DE in-service teacher trainees in Botswana colleges of primary education. All the students specialised in Languages (English and Setswana). For studies in English, the course consisted of language and linguistics, literature and language teaching methodologies. The course rationale, as stated in the Colleges of Education Diploma in Primary Education Curriculum (Ministry of Education and skills Development, 2010: 76), 'is to [produce] teachers whose spoken and written English is of high standard and will be good models for their learners'.

We conducted this research in possession of a research permit granted by the Botswana Ministry of Education and Skills Development. With this permission, the first author of this article went to different regional Education offices, where she had to consult the regional directors to 
communicate with the principals of schools affected to grant further permission to conduct interviews with the sample population of the participants.

Ethical clearance to conduct the study was obtained from the institutions involved in the study and informed consent was obtained from the research participants.

\section{Purpose and objectives of the research}

The purpose of this study was to determine the reading experiences, habits and practices of primary school in-service teacher trainees, in order to determine their reading patterns and the degree to which they appreciate and recognise the literary elements in the primary school curriculum. This purpose was approached through answering each of the following two questions:

1. What are trainees' attitudes towards literature as a subject?

2. What are the reading patterns of the teacher trainees?

The answers to these questions were compared and integrated to present a coherent picture of the in-service teacher trainees, their studies and attitudes.

In the next section, the results from the questionnaires and the interviews are discussed. The data from these two instruments provided a picture of the reading culture that prevailed in this case. The interviews made it possible to enhance the picture provided in the questionnaires.

\section{DATA COLLECTION: QUESTIONNAIRES AND INTERVIEWS}

\section{Questionnaires: format and results}

The questionnaires (see Addendum 1 for the questionnaire) were distributed to all 25 in-service trainees who were registered for the DPE-DE specialising in language teaching in the 2008 cohort. Nineteen questionnaires were returned. All the respondents were female. All attempts to follow up with the other respondents about returning the completed questionnaires were in vain. In accordance with ethical procedures, it was therefore assumed that these respondents chose not to participate in the study.

The first part of the questionnaire determined the demographic profile of the research participants, as summarised in Table 1.

Table 1: Summary of the findings on profiles of the participants

\begin{tabular}{|l|l|l|l|l|l|l|}
\hline Code & Qualification & $\begin{array}{l}\text { Age in } \\
\text { complete } \\
\text { years }\end{array}$ & $\begin{array}{l}\text { Highest } \\
\text { qualification } \\
\text { pre-DPE-DE }\end{array}$ & $\begin{array}{l}\text { Teaching } \\
\text { experience }\end{array}$ & $\begin{array}{l}\text { Area of } \\
\text { teaching post }\end{array}$ & $\begin{array}{l}\text { Secondary school } \\
\text { level English language } \\
\text { final grades }\end{array}$ \\
\hline 01 & DPE & 44 & BGCSE & $16-20$ & Semi-urban & C \\
\hline 02 & DPE & 40 & COSC & $16-20$ & Rural & C \\
\hline 03 & DPE & No answer & PTC & $16-20$ & Remote & B \\
\hline 04 & DPE & 52 & PTC & $21+$ & Semi-urban & C \\
\hline 05 & DPE & 51 & PSLE & $21+$ & Urban & Unclassified \\
\hline 0 & DPE & No answer & PTC & $21+$ & Rural & C \\
\hline
\end{tabular}




\begin{tabular}{|l|l|l|l|l|l|l|}
\hline 07 & DPE & 43 & JC & $21+$ & Rural & B \\
\hline 08 & DPE & 45 & PTC & $16-20$ & Semi-urban & C \\
\hline 09 & DPE & 43 & PTC & $21+$ & Semi-urban & C \\
\hline 010 & DPE & 49 & PTC & $21+$ & Rural & B \\
\hline 011 & DPE & 42 & PTC & $16-20$ & Rural & D \\
\hline 012 & DPE & No answer & JC & $21+$ & Rural & C \\
\hline 013 & DPE & No answer & JC & $21+$ & Remote & C \\
\hline 014 & DPE & 44 & PTC & $16-20$ & Semi-urban & B \\
\hline 015 & DPE & No answer & JC & $21+$ & Rural & B \\
\hline 016 & DPE & 46 & BGCSE & $21+$ & Rural & C \\
\hline 017 & DPE & No answer & PTC & $21+$ & Rural & C \\
\hline 018 & DPE & 49 & PTC & $21+$ & Urban & C \\
\hline 019 & DPE & 44 & JC & $16-20$ & Rural & C \\
\hline
\end{tabular}

In Table 1, it is clear that the ages of the in-service trainees ranged from 40 to 55 . Despite the omission of age in some questionnaires, it is safe to conclude from our knowledge of this cohort that the absent answers fell in the same age category. This conclusion is echoed in the teaching experience of all the respondents ranging from 16 to $21+$ years.

After the questions about the demographic profile of the student teachers, questions about reading habits followed. The answers to the question on their leisure reading were expected to reflect a positive attitude towards reading, because of an expectation that the outcome would reveal a variety of materials being read by the participants in their free time. The majority (14) enjoyed reading novels or storybooks. Next in popularity was the reading of newspapers and magazines (13 each). The least enjoyed reading materials were 'textbooks', 'government policies' and DPE-DE instructional materials (modules), which only one person listed as favourite leisure reading material. Two participants mentioned enjoying reading the Bible and other religious publications. The reference to 'study modules and textbooks' apparently indicated the participants' lack of comprehension of the meaning of leisure reading in the question.

The findings on reading materials that the teacher trainees enjoyed reading in their free time are presented in Table 2.

Table 2: Summary of findings of participants' reading habits

\begin{tabular}{|l|l|l|}
\hline Reading material & $\begin{array}{l}\text { Number of times the } \\
\text { material is mentioned as } \\
\text { favourite leisure reading }\end{array}$ & $\begin{array}{l}\text { Popularity expressed } \\
\text { in \% }\end{array}$ \\
\hline Novels/storybooks & 14 & 31.1 \\
\hline Newspapers & 13 & 28.9 \\
\hline Magazines & 13 & 28.9 \\
\hline The Bible/religious material & 2 & 4.5 \\
\hline Textbooks & 1 & 2.2 \\
\hline Government policies & 1 & 2.2 \\
\hline DPE-DE modules & 1 & 2.2 \\
\hline
\end{tabular}

In response to questions about their reading habits and how they encouraged their pupils to read Per Linguam 2018 34(2):30-51 
(section B of the questionnaire in Addendum 1), it seemed that participants' attitudes to leisure reading were positive. However, the impact of their literature studies on their teaching of literature and on sharing their reading materials fell short of expectations, and did not match their enthusiasm when encouraging their pupils to read for pleasure. Much of what the teachers reported was what the learners were encouraged to do by the curriculum (see the section above on the curriculum for primary school English in Botswana). The pupils, for instance, brought some reading materials from home to add to the stock in the library corners. In the teachers' reports, there was neither a specific indication that they read stories to the pupils, nor that they read some stories with their pupils. Reading together would display the teacher modelling reading behaviour for the pupils. In our view, sharing favourite titles or even reading some parts to the pupils would have proved to them that their teachers valued reading and that they should copy this behaviour. From the responses, it was also clear that the in-service teacher trainees had to improve the post-reading activities in their ESL classrooms, so that the impact of their literature studies at DPE-DE level may be reflected in their pupils' attitudes towards leisure reading.

\section{Interviews}

Of the 19 teachers, seven agreed to be interviewed. The standards taught and the research sites are presented in Table 3.

Table 3: Standards taught and research sites

\begin{tabular}{|l|l|l|}
\hline Interviewee & Standard taught & School setting \\
\hline 09 & Seven & Kanye semi-urban \\
\hline 011 & Five & Moshupa rural \\
\hline 01 & One & Serowe semi-urban \\
\hline 07 & Four & Mothabaneng rural \\
\hline 08 & Five & Pitsane semi-urban \\
\hline 019 & Five & Dinatshana rural \\
\hline 018 & One & Lobatse urban \\
\hline
\end{tabular}

The interviewees were representative of all levels, lower and upper primary, and their settings covered most geographical areas - urban, rural and semi-urban.

To determine the teachers' backgrounds with regard to literature studies prior to the DPE-DE qualification, the interviewees were asked whether they had studied literature at secondary level. The majority (6) had studied literature at secondary level; four at JC level (the first three years of secondary school); two at Cambridge Overseas School Certificate level (COSC - the last two years at secondary level). Only one respondent had no background content knowledge in literature.

\section{QUALITATIVE DATA ANALYSIS}

The qualitative data went through a process of content analysis, which involved coding and analysing data at two levels (Hancock, 2002: 17): a descriptive account of the data, as well as an interpretative account. We continually revisited the data and reviewed the categorisation of the data to ensure that the themes that emerged offered sufficient and accurate descriptions of the 
results. Various themes emerged from the data, and as we identified the themes, we coded them into categories, which were not watertight, because some of the themes overlapped to an extent.

In the section below, the themes are reported under the following headings:

- Reading literature and reading performance

- Attitudes towards literature studies

- Strategies for the reading lessons

- Resources for leisure reading

\section{Reading literature and reading performance}

The participants were asked about the literary texts that they had studied at diploma level, and whether they had shared the stories from the texts with their pupils. The intention of these questions was to ascertain the attitudes of the participants towards their literature studies. Surprisingly, none of the participants could remember the authors and full titles of the texts that they claimed to have studied less than six years previously. This response is not characteristic of avid readers, who presumably are well acquainted with book titles and author names. Examples of questions and responses regarding literature texts they had studied are:

Researcher: Can you recall the titles of the literature texts that you studied?

Interviewee: I cannot remember because we are just given modules, we are reading from the modules.

Researcher: Do you remember the texts that you were studying?

Interviewee: In English there were no books. But they are the ones that are written in the modules.

Interviewee: They were two of them, 'Jewels'.

Researcher: So do you remember the titles of the text you were studying at diploma level?

Interviewee: There was one book, it was written by Wole Soyinka and there were extracts like, something like metamorphosis.

Researcher: Brother Jero's metamorphosis.

It was noted as a major problem that, at diploma level, teacher trainees had to discuss extracts from literature texts instead of placing more emphasis on reading the whole text. Participants' references to the modules refer to the reading and discussion of literature based on synopses found in the instructional materials (modules). This strategy does not promote or remedy teachers' PCK. Reading a text would, for example, unpack all the characters and thus make it possible for the student to analyse character development, identify and evaluate themes and symbols, and express their opinions and feelings on the text as a whole.

The findings therefore portrayed a type of performativity on the part of in-service teacher trainees; there was no actual engagement with literature. Interaction with literary texts would have meant that the trainees had an opportunity to enjoy some of the typical analytical activities that are normally expected of students of literature. Such activities include analysing the plot structure, identifying literary devices and evaluating their effectiveness in the context of the text, discussing character development, and evaluating the coherence of thematic elements such as 
symbols and imagery. All these are examples of the literary PCK that teachers need.

\section{Attitudes towards literature studies}

A further enquiry into in-service teacher trainees' attitudes towards literature studies asked the interviewees whether they looked forward to literature tutorials and, if so, to share their experiences. The intention of the question was to highlight their habits and perceptions about literature.

Two categories emerged under this theme. The first one represented favourable attitudes. For some of the interviewees, the tutorials were interesting, and they acknowledged that lessons from literature tutorials had helped them to apply most of the objectives in the syllabus in Standard 5, for example the objectives under 'Reading a story'. Literature studies in their classrooms enabled them to not just ask general questions, but to discuss characterisation - pupils expressed feelings about characters, thus developing their analytical skills.

The second category represented those who found the tutorials boring. These interviewees had negative experiences because they had not read any texts included in the literature tutorial. Instead, they had to go to the library to read the texts, and then shared the stories with the rest of the tutorial group. Very few were eager to go to the library to read the texts, and these were the ones expected to share the stories in the literary texts with the rest of the class. Thus, the tutorials became boring because others were not very enthusiastic about reading the texts themselves.

Some interviewees misunderstood the question, and mentioned the benefits of literature studies: Literature improves on learners' vocabulary. Some stated that reading impacts on pupils' ability to write: For a child to write the word, it is when he or she knows how to read it. The responses were an indication that the teacher trainees, at best, had mixed attitudes towards literature studies and, at worst, avoided the reading of literary texts altogether. Some perceived the impact of literature studies on their pupils, and they presented the benefits that were achieved by the pupils. Others experienced a void due to studying literature without reading texts. With these mixed responses in mind, the next section reports the strategies employed by the teachers to encourage reading in their classes.

\section{Strategies employed by teacher trainees in reading lessons}

Since the participants in this project were in-service trainees, it was possible to ask them about their teaching practices. The first big category in this theme was the role of learners in the reading lesson. The majority of the respondents mentioned that they afforded all pupils in a class the opportunity to read in various ways. Some classes started with the teacher reading a text out loud and the whole class reading after the teacher. In other instances, they had each pupil either read a paragraph or a sentence. All methods were aimed at giving all pupils an opportunity to read. Below is what some of the respondents said about the strategies that they employed in reading lessons:

First I will, if it's for a start, maybe, I am teaching the lower standards. I read the story first myself, then I will let the pupils read after me and then they will read for themselves but these ones because now I am with them for the third year now, they are familiar with 
reading. I will just let them read paragraph by paragraph. Paragraph, one child, another child will read the other paragraph. The other by another child, but read each and every paragraph. After reading we explain it as a class.

To the question 'What kind of questions do you ask sometimes?', a typical response was:

Like maybe if they don't understand the meaning of some of the words in the text, they will ask and then I will explain to them.

The expectation is that, in upper primary classes, the pupils and the teacher read a text together, discuss the text and the teacher asks questions to test pupils' comprehension orally. For literature-related discussions, the class discusses characterisation and setting with the teacher. Pupils would also express the feelings that different characters evoke, in order to develop analytical skills.

The second category in this theme related to the explicit mention of literature. Some respondents mentioned the use of literature in language teaching. Most of them acknowledged that literature assists pupils in building vocabulary and improving their sentence structures, especially in instances where teachers insist on pupils answering questions in full sentences. In some instances, teachers replaced the multiple-choice questions that accompany comprehension exercise with their own questions in order to encourage the pupils to answer in full sentences and to improve other aspects of grammar, for example, punctuation. However, one of the respondents mentioned how teaching a mixed ability group made it difficult to try out some other strategies, because some pupils were very weak in reading, and therefore struggled to comprehend what they read. The respondent, however, did not offer a solution for addressing this weakness.

\section{Availability of resources}

Two main categories emerged from this theme, the first relating to resources within the school and the second to resources outside the school.

In the first category, all respondents mentioned that they had a library corner in their classrooms, from which the pupils could access leisure reading. For lower primary, this library corner mainly comprised word cards and pictures to enable pupils to practise their reading of the words. In the upper classes, the library corners had newspapers, magazines and some textbooks, but few storybooks. The respondents mentioned that the library corners were understocked. The purpose of the library corners was really to afford pupils an opportunity to read. The pupils were usually encouraged to share what they read with the rest of the class, though this was minimal. Sufficient time to read was given during lessons. When pupils had completed assigned work, they were allowed to select something from the corner to read. According to the respondents, however, the library corners were not equipped adequately to support the pupils in their quest to find reading matter.

According to the respondents, all schools did not have school libraries. Four of the participants mentioned the presence of this infrastructure in their schools, but all lamented the fact that libraries were understocked. One of the participants mentioned that the school library: 
has got some books, even though the primary schools they are not catered for. The books that we are given are not enough like in the secondary, the primary schools are not provided with a lot of books like in secondary schools.

Another lamented the lack of replenishing the stock of books:

There are books in the library, I came here in 2010 and we have never changed them, old stock. But myself I feel it is just okay why because reading is reading. If the kids they have, if there are books there for the kids to read, that is what helps them.

In all cases, participants had to convert some underutilised room, for example a storeroom, into a school library. The facilities we don't have. Our library is just a small storeroom was the message that one conveyed. So, in most cases, they were not only faced with a lack of reading materials in the library, but also the challenge of capacity. All, however, mentioned that the timetable provided for a library class, which gave all pupils in a school an opportunity to visit the library and engage in some reading. This exercise was cherished by many pupils and they were reported to have reminded the teachers whenever they seemed to have forgotten the library period.

In terms of resources outside of the school, only three respondents mentioned using the national libraries found in some places in Botswana. All of the participants mentioned that their pupils had not registered for membership of the library. Furthermore, they lamented the fact that pupils visiting the library spent more time playing computer games than reading. The teacher trainees also did not express any enthusiasm in encouraging their pupils to register as members of the national library. For instance, this is what one of the respondents had to say about membership of the national library:

Researcher: Are your pupils members of the National Library?

Interviewee: I don't think so.

Researcher: You don't think so? You haven't talked to them about going to the library? Interviewee: Seriously I didn't.

An avid reader would go out of his or her way to find leisure resources, even in situations where the resources are scarce. Participants did not seem eager to encourage their learners to utilise the free resources offered by national libraries in their areas.

In this section, we have reported what the teacher trainees cited in the interviews as their strategies in the ESL classroom; resources that they were able to access or harness in order to realise their efforts to cultivate a culture of reading in their pupils; the respondents' readership; what they read for leisure; and whether they shared what they read with their pupils. The efforts depicted here reflect adversely on the reading behaviour of the in-service teacher trainees. They did not present themselves as enthusiastic readers, and this habit was what modelled for their pupils.

\section{DISCUSSION OF FINDINGS}

Pivotal to the findings of the questionnaire and the interviews is Powell-Brown's (2003/2004: 
284) simple but provocative question: 'Can you be a teacher of literacy if you don't love to read?' Gomez (2005: 92), in response to Powell-Brown's question, posed a similar question: 'Why would you be a teacher of literature if you don't love to read?'

From the first theme, where interviewees' experiences with literature during their training were detailed, their lack of engagement was clearly visible. McKay (1982: 531) states that student interaction with literary texts will improve reading proficiency, which further contributes to the achievement of a student's academic and occupational objectives. In studying literature, teacher trainees need to be encouraged to adopt an analytical mindset and to develop personal opinions on the texts they read, instead of repeating opinions that they find elsewhere about the texts, for example in their study guides. Moreover, how would they develop any kind of critical ability if they only read synopses of the literary works in their course materials? Hismanoglu (2005: 52) rightly maintains that literature promotes students' critical thinking when they have different perceptions and prior knowledge of a literary text. One major point from the findings of the investigation is that the in-service teacher trainees did not have the opportunity to read the literature texts that could have improved their critical thinking skills to enable them to form personal opinions. This probably also explains their failure to remember the titles and authors of the texts that they had studied.

The questionnaire responses show that, although the teacher trainees engaged in leisure reading, they were not really avid readers. Their emphasis was on reading newspapers, magazines and novels, as could be seen from what they communicated in the questionnaires and interviews. For teachers to encourage their pupils' reading habits, they must become models of reading themselves to show their pupils that they value and enjoy reading. The teacher trainees' INSET curriculum, which included literature studies without ensuring that literature texts were actually read, had a significant impact on their teaching practices. They did not emphasise or share leisure reading with their pupils, which was worsened by the inadequate resources available for them to inculcate a reading culture in their pupils. If they cannot identify their pupils' problems, it could point to a lack of PCK, in terms of which the teacher ought to be able to identify pupils' needs and provide a solution from the content knowledge that he or she possesses.

More depressing from these findings is that, although teacher trainees employed varied strategies in order to develop their PCK according to the needs of their pupils, they still fell short of serving as a primary source for pupils' understanding of reading for leisure and did not develop a positive attitude towards reading literature. For instance, the in-service teacher trainees did not encourage their pupils to register for membership of national libraries in order to embrace the free resources at their disposal. By and large, they left it to the learners to bring materials to class. 


\section{CONCLUSION}

It is easy to say that a particular community does not have a reading culture, but what would a reading culture look like and why is it important to have such a culture? This study argues that a culture of reading and appreciating literature is important not only for personal development, but also for the development of critical thinking and the development of PCK. We focused on getting answers from teacher trainees about their reading habits and their perceptions of literature and literature teaching, and from their responses it is possible to say what a reading culture is not, at least among the participants in this research project.

Firstly, the study points to the significance of initial literacy development. We need to note in particular that the lower primary level is usually focused on developing reading skills and comprehension (literacy): this is where the love of reading and literature starts, even when this happens in another language (Setswana). As the start of literature teaching, what the pupils learn in Setswana in Standard 1 should be applicable to English.

Secondly, this study has exposed the dire situation of the teacher trainees' in-service training regarding the teaching of literature. The most disturbing data that this study has yielded constitute the fact that the trainees' study of literature was focused more on the study of synopses of literary texts rather than the actual reading and analysis of the texts themselves. One can hardly expect of teachers to translate literary concepts into PCK if they have not gained any experience of their own in analysing and evaluating full literary texts. A study of literature that is devoid of literary texts or even the willingness to get a text from the library cannot but hamper these trainees' classroom decisions in terms of teaching literature to their ESL pupils. The in-service teacher trainees did not seem to display a passion for reading. One cannot talk of a culture of reading when students do not read, are not interested in finding the original texts, are bored by the tutorials in which the texts are discussed and, despite these deficiencies, are rewarded by passing their English modules. In addition, lack of infrastructural resources, such as libraries and other reading material resources, impacted greatly on the potential for trainees to develop content knowledge as the foundation for the development of PCK.

From the perspective of the themes that emerged from the interviews, one could argue that as far as this study goes, primary school teachers of English, and particularly lower primary school teachers, do not see themselves as teachers of literature. It would probably be fair to say that part of the blame for this perception can be attributed to the curriculum. The primary English curriculum that the trainees have to teach is divided into two syllabi, lower and upper primary. In the lower primary syllabus, the emphasis is on equipping pupils with reading and writing proficiency, and it is only in the final year of this level (Standard 4) that elements of literary PCK can be found; teachers are expected to show awareness of different genres and of character and dialogue in stories. At upper primary level, the syllabus (Department of Curriculum Development and Evaluation, 2011: 3) states that pupils are expected, by the end of Standard 7, to have further developed the language skills of listening, speaking, reading and writing to be able to 'read independently for information and pleasure different types of literature, including poetry, drama and prose within a basic vocabulary level of 2000 words'. In other words, if teacher trainees are focused solely on the curriculum for their particular level and do not see themselves as part of an ongoing process of preparation for the next school phase, their lack of deeper interpretation of the 
curriculum could contribute to the fact that they see themselves merely as teachers of language, and not also teachers of literature.

It is further problematic that the primary English syllabus lacks clear direction to teachers, by failing to include a list of literary texts to be studied by the pupils and thereby possibly reinforcing the trainees' perception that literature teaching only happens at upper primary level. The teachers are expected to infuse literature teaching through the reading materials of their choice, including poetry, drama and prose. Generally, literature lessons at primary school level are regarded simply as reading lessons.

It is clear from this study that the source of the knowledge base (teacher trainees' INSET programme) did not lay a foundation for a solid knowledge base. This problem has a knock-on effect with regard to the development of adequate PCK. It is impossible to harness content knowledge (of literary analysis) for pedagogical purposes if it is not available. As a consequence, pedagogical reasoning and action are flawed. The implications for teaching policies and educational reform cut across government resources, curriculum development and teacher empowerment.

\section{REFERENCES}

APPLEGATE, MD \& AJ APPLEGATE. 2004. The Peter effect: reading habits and attitudes of pre-service teachers. The Reading Teacher, 57:554-560.

Botswana Government. Towards Prosperity For All, Presidential Task Group for A Long Term Vision for Botswana, September 1997.

CAIRNEY, TH. 2011. The place of literature in an increasingly virtual world. Springer. Sydney

CALVO, M. 2012. Teaching literature in the EFL/ESL classroom. Available from http://literaturetoteachenglish.blogspot.com/p/about-literature.html Accessed 14 March 2015.

CRESWELL, JW. 2003. Research design: qualitative, quantitative and mixed methods approaches (2nd ed.). London: SAGE.

CURRICULUM DEVELOPMENT \& EVALUATION, 1997. Curriculum Blueprint, Senior Secondary Programme March 1997, Gaborone: Department of Education.

Ministry of Education and skills Development. 2010. Colleges of Education Diploma in Primary Education Curriculum (Draft). Ministry of Education and skills Development. Gaborone

GOMEZ, K. 2005. Teachers of literacy, love of reading, and the literate self: a response to Ann Powell-Brown. Journal of Adolescent \& Adult Literacy, 49(2):92-96.

HANCOCK, B. 2002. Trent focus for research and development in primary health care: an introduction to qualitative research. Trent Focus Group. University of Sheffield.

HERNANDI, P. 2002. Why is literature: a co-evolutionary perspective on imaginative worldmaking. Poetic Today, 23(1):21-42.

HISMANOGLU, M. 2005. Teaching English through literature. Journal of Language and Linguistic Studies, 1(1):53-65.

MALABA, MZ. 2006. Literature and humanistic values. In Arua, AE, M Bagwasi, T Sebina \& B Seboni (eds), The study and use of English in Africa. Newcastle: Cambridge Scholars Press. McKAY, S. 1982. Literature in the ESL classroom. TESOL Quarterly, 16(4):529-536.

University of Botswana, English Department. 1993. National Conference on Literature in 
Language Teaching. Gaborone

POWELL-BROWN, A. 2003/2004. Can you be a teacher of literacy if you don't love to read? Journal of Adolescent \& Adult Literacy, 47:284-288.

DEPARTMENT OF CURRICULUM DEVELOPMENT AND EVALUATION. 2011. Primary English syllabus. Gaborone: Ministry of Education.

DEPARTMENT OF CURRICULUM DEVELOPMENT AND EVALUATION. 1998. Senior secondary school syllabus: Literature in English. Gaborone: Ministry of Education.

SHULMAN, L. 1986. Those who understand: knowledge growth in teaching. Educational Researcher, 15(2):4-14.

SHULMAN, LS. 1987. Knowledge and teaching: foundations of the New Reform. Harvard Educational Review, 57(1):1-23.

SMIT, T. 2009. The role of African literature in enhancing critical literacy in first-generation entrants at the University of Namibia. Unpublished doctoral dissertation, Stellenbosch University, Stellenbosch.

\section{BIOGRAPHICAL NOTES}

Deborah V Sanoto is a Lecturer in the Department of Teacher Education in the School of Education at Botswana Open University. She is interested in the teaching of literature in English and curriculum development and studies in the context of teacher training.

Christa van der Walt is professor in the Department Curriculum Studies in the Faculty of Education at Stellenbosch University. She is interested in the teaching of English in multilingual contexts. 


\section{APPENDIX A: QUESTIONNAIRE}

\section{Dear Sir/Madam}

My name is Deborah Sanoto, I am undertaking a research project to determine the reading experiences, habits and practices of Botswana's Primary School in-service teacher trainees who have studied English language and literature. Therefore, I kindly request that you complete the following short questionnaire in order to help me to assess the extent to which literature is integrated and appreciated in English studies component of the curriculum and on the leaners. It should take no longer than 15 minutes of your time.

Please do not enter your name or contact details on the questionnaire. It will remain anonymous, and information provided by you will remain confidential.

Kindly return the completed questionnaire to me in the postage paid return envelope on or before 1 October 2013.

Should you have any queries or comments regarding this study, you are welcome to contact me by telephone at 71624958/ 3646013 or e-mail me at dsanoto@ bocodol.ac.bw.

Thank you

Yours faithfully

D V Sanoto (The Researcher)

PLEASE ANSWER THE FOLLOWING QUESTIONS BY CROSSING (X) THE RELEVANT BLOCK OR WRITE DOWN YOUR ANSWER IN THE SPACE PROVIDED.

EXAMPLE of how to complete this questionnaire:

Your gender?

If you are female

Male 1

Female

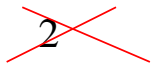

\section{Section A - Background information}

This section of the questionnaire refers to background or biographical information. I am aware of the sensitivity of the questions in this section, but the information will make it possible for me to compare groups of respondents. Once again, I assure you that your response will remain anonymous. Your co-operation is appreciated. 
1. Gender

Male

Female

2. Age (in completed years)

3. Years of teaching

$0-5$ years 1

6-10 years 2

11-15 years 3

$16-20 \quad 4$

$21+$ more years $\quad 5$

4. Your highest educational qualification prior to DPE-DE?

Primary School leaving Examination 1

(PSLE)

Junior Certificate in Education (JCE) 2

Cambridge Overseas School Certificate 3

(COSC)

Botswana General Certificate in Secondary 4

Education (BGCSE)

Primary Teacher's Certificate (PTC) 5

5. How would you describe the area in which you are teaching?

Urban

Semi-urban 2

Rural 3

Remote 4

6. What were your secondary school level grades in English Language final examinations?

A or above 1

B Grade 2

C Grade $\quad 3$

D or below 4

Unclassified (U) $\quad 5$

\section{Section B}

This section of the questionnaire explores your reading habits and practices in your English language teaching classroom. Please answer the questions in the spaces provided.

7. In your free time what reading materials do you enjoy reading for leisure? 
8. In what ways do you encourage your learners to read for pleasure?

9. What type of reading materials do you keep in your home library?

10. Do you keep any set of readers at school to share with your learners? If yes, describe the type of reading materials.

Thank you for your co-operation in completing this questionnaire. Kindly return the questionnaire as specified in the cover letter. 